\title{
Successful Treatment of Refractory Thrombotic Thrombocytopenic Purpura with Cyclosporine and Corticosteroids in a Patient with Systemic Lupus Erythematosus and Antibodies to ADAMTS13
}

\author{
Terukazu Enami, Takeshi Suzuki, Satoshi Ito, Ai Yoshimi, Makoto Sugihara, \\ Mizuko Mamura, Taichi Hayashi, Daisuke Goto, Isao Matsumoto, \\ Akito Tsutsumi and Takayuki Sumida
}

\begin{abstract}
A 46-year-old woman with systemic lupus erythematosus was hospitalized for purpura, hematochezia and hematuria. One week after admission, she developed grand mal seizures and coma and was diagnosed with thrombotic thrombocytopenic purpura (TTP) when fragmented red cells were found on the peripheral blood smear. Laboratory findings showed severe ADAMTS13 (a disintegrin-like and metalloprotease with thrombospondin type 1 repeats) deficiency and anti-ADAMTS13 antibodies, which in recent reports have indicated a poor prognosis. She was refractory to methylprednisolone pulse therapy and plasma exchange, but administration of cyclosporine induced remission without adverse effects. We propose that cyclosporine may be an effective treatment for cases of refractory TTP.
\end{abstract}

Key words: thrombotic thrombocytopenic purpura (TTP), systemic lupus erythematosus (SLE), cyclosporine

(DOI: 10.2169/internalmedicine.46.6192)

\section{Introduction}

Thrombotic thrombocytopenic purpura (TTP) is a rare but life-threatening disease. It is associated with thrombi, composed primarily of platelets, in affected organs. Recently, a mechanism for platelet consumption in TTP has been elucidated. Von Willebrand factor (vWf) is synthesized in endothelial cells and assembles in large multimers that are present in normal plasma. These multimers, called unusually large von Willebrand factor (ULVWf), are rapidly degraded in the circulation to normal size range VWf multimers by a specific von Willebrand factor-cleaving protease (ADAMTS13; a disintegrin-like and metalloprotease with thrombospondin type 1 repeats) (1-4). A deficiency of ADAMTS13 or an autoantibody directed against it is responsible for some cases of TTP, leading sequentially to accumulation of ULVWf multimers, platelet aggregation, and the thrombosis that is characteristic of the disease (5).
Based on clinical studies, plasma exchange (PE) with fresh frozen plasma is effective and is performed as an initial treatment for TTP. It is considered that PE can remove some acquired autoantibodies (such as anti-ADAMTS13) and ULVWf multimers, and plasma infusion presumably supplies the missing enzyme. However, some patients become either refractory to or dependent upon PE. Recent studies have demonstrated that adult-onset TTP patients with detectable anti-ADAMTS13 antibodies tend to have a worse prognosis than those without the antibody, with a refractory and often relapsing course (6-8). Here we report a case of refractory TTP with anti-ADAMTS13 antibodies in a patient with systemic lupus erythematosus (SLE) who was successfully treated with cyclosporine and achieved disease remission.

\section{Case}

In August 2004, a 46-year-old Japanese woman with SLE

Clinical Immunology, Advanced Biomedical Applications, Graduate School of Comprehensive Human Sciences, University of Tsukuba, Tsukuba Received for publication August 21, 2006; Accepted for publication March 13, 2007

Correspondence to Dr. Satoshi Ito, s-ito@md.tsukuba.ac.jp 
Table 1. Laboratory Findings on Admission

\begin{tabular}{|c|c|c|c|c|c|c|c|}
\hline \multicolumn{2}{|l|}{ Urine } & \multicolumn{6}{|c|}{ Blood chemistry } \\
\hline Protein & $(1+)$ & AST & 32 & $\mathrm{IU} / \mathrm{I}$ & $\mathrm{Na}$ & 141 & $\mathrm{mEq} / \mathrm{l}$ \\
\hline Sugar & $(-)$ & ALT & 15 & $\mathrm{IU} / \mathrm{I}$ & $\mathrm{K}$ & 3.8 & $\mathrm{mEq} / \mathrm{l}$ \\
\hline Occult blood & $(-)$ & $\gamma-\mathrm{GTP}$ & 13 & IU/I & $\mathrm{Cl}$ & 103 & $\mathrm{mEq} / \mathrm{l}$ \\
\hline \multirow[t]{2}{*}{ Bilirubin } & $(-)$ & LDH & 821 & IU/I & BUN & 16.7 & $\mathrm{mg} / \mathrm{dl}$ \\
\hline & & ALP & 179 & IU/I & $\mathrm{Cr}$ & 0.62 & $\mathrm{mg} / \mathrm{dl}$ \\
\hline blood count & & T.Bil & 1.7 & $\mathrm{mg} / \mathrm{dl}$ & UA & 5 & $\mathrm{mg} / \mathrm{dl}$ \\
\hline WBC & $8300 / \mathrm{mm}^{3}$ & TP & 6.6 & $g / d l$ & $\mathrm{Fe}$ & 97 & $\mu \mathrm{g} / \mathrm{dl}$ \\
\hline Neutro $83.7 \%$ & & Alb & 3.5 & $g / d l$ & TIBC & 220 & $\mu \mathrm{g} / \mathrm{dl}$ \\
\hline $\begin{array}{ll}\text { Lym } 3.8 \% & \text { Eo } 0.0 \% \\
\text { Mo } 10.5 \% & \text { Ba } 1.0 \%\end{array}$ & & CRP & 0.16 & $\mathrm{mg} / \mathrm{dl}$ & ferritin & 126.9 & $\mathrm{ng} / \mathrm{dl}$ \\
\hline RBC & $313 \times 10^{4} / \mathrm{mm}^{3}$ & coagulat & & & & & \\
\hline $\mathrm{Hb}$ & $8.9 \mathrm{~g} / \mathrm{dl}$ & PT-INR & 1.01 & & & & \\
\hline $\mathrm{Ht}$ & $27.8 \%$ & APTT & 38.2 & sec & & & \\
\hline Plt & $0.7 \times 10^{4} / \mathrm{mm}^{3}$ & FDP & 3.8 & $\mu \mathrm{g} / \mathrm{dl}$ & & & \\
\hline \multicolumn{8}{|l|}{ Immunogogical } \\
\hline $\operatorname{Ig} G$ & $1613 \mathrm{mg} / \mathrm{dl}$ & RF & & & & 2 & $\mathrm{IU} / \mathrm{ml}$ \\
\hline $\operatorname{Ig} A$ & $341 \mathrm{mg} / \mathrm{dl}$ & \multicolumn{4}{|c|}{ ANA(homogeneous) } & 80 & \\
\hline IgM & $94 \mathrm{mg} / \mathrm{dl}$ & \multicolumn{4}{|c|}{ anti-ds DNA antibody (RIA) } & 10.9 & $\mathrm{IU} / \mathrm{ml}$ \\
\hline C3 & $40 \mathrm{mg} / \mathrm{dl}$ & \multicolumn{4}{|c|}{ anti-ds DNA antibody (ELISA) } & 21 & $\mathrm{IU} / \mathrm{ml}$ \\
\hline C4 & $2 \mathrm{mg} / \mathrm{dl}$ & \multicolumn{4}{|c|}{ anti-CL $\beta$ 2GPI } & $<1.2$ & $\mathrm{IU} / \mathrm{ml}$ \\
\hline $\mathrm{CH} 50$ & $5.8 \mathrm{IU} / \mathrm{ml}$ & \multirow{2}{*}{\multicolumn{4}{|c|}{ lupus anticoagulant }} & 1.3 & \\
\hline & & & & & & 3 & $\mu \mathrm{g} / \mathrm{dl}$ \\
\hline
\end{tabular}

and myasthenia gravis (MG) was admitted to our hospital because of purpura, hematochezia and hematuria.

In 1990, she had been diagnosed with idiopathic thrombocytopenic purpura (ITP) and started on $30 \mathrm{mg}$ /day of oral prednisolone (PSL). In 1993, she developed arthralgia with severe thrombocytopenia (platelet count $0.4 \times 10^{4} / \mu \mathrm{l}$ ). She was positive for antinuclear antibody (ANA) (homogeneous 80 ) and anti-double stranded DNA antibody (16 U/ml), and was diagnosed with SLE. She had no significant organ involvement. Oral PSL was increased to $60 \mathrm{mg} /$ day then gradually tapered. In January 1999, she began to suffer from muscle weakness of the extremities, diplopia and dysphagia. She was diagnosed with myasthenia gravis after a positive tensilon test and a positive repetitive nerve stimulation study, and a thymectomy was performed. Following this she had no symptoms of SLE or MG. Her titer of anti-DNA antibody was 5 to $10 \mathrm{IU} / \mathrm{ml}$, her lymphocytes count stayed at about $1,000 / \mu \mathrm{l}$ and her complement level was about $7 \mathrm{U} / \mathrm{ml}$. There was no proteinuria or hematuria.

In July 2004, while on 15 mg/day of oral PSL, she developed purpura, hematochezia and hematuria, and her platelet count was $0.7 \times 10^{4} / \mu$ l. Physical examination on admission showed the patient to be lucid and afebrile. Her blood pressure was $118 / 72 \mathrm{mmHg}$ and her pulse rate $86 \mathrm{bpm}$ and regular. There was mild tenderness in the upper abdomen without rebound, guarding or hepatosplenomegaly. Purpura was present in the extremities. Laboratory findings on admission revealed severe thrombocytopenia and a hemolytic anemia, with lowered haptoglobin and elevated bilirubin and lactate dehydrogenase. A coagulation screen was normal. ANA and double-stranded DNA antibodies (by RIA and ELISA methods) were slightly elevated (Table 1). Bone marrow aspirate showed increased numbers of megakaryocytes. She was considered to have an exacerbation of throm- bocytopenia caused by SLE and the dose of PSL was raised from $15 \mathrm{mg} /$ day to $60 \mathrm{mg} /$ day, but the platelet count did not increase..

On day 7 after admission, she developed transient syncope with fever. Computed tomography scan and magnetic resonance imaging revealed no evidence of cerebral hemorrhage or infarction. Fragmented red blood cells (RBC) were observed on the peripheral blood smear. Because of fragmented red blood cells, worsening anemia and syncope, she was regarded as having TTP and was transfused with 6 units of fresh frozen plasma (FFP). Her diagnosis was confirmed with the finding of von Willebrand factor-cleaving protease (ADAMTS13; a disintegrin-like and metalloprotease with thrombospondin type 1 repeats) activity at less than $3 \%$ of normal, and an inhibitory autoantibody to ADAMTS13 was found on a blood test on day 7.

On day 8 , the platelet count decreased to $0.5 \times 10^{4} / \mu \mathrm{l}$, renal function deteriorated, creatinine was $1.2 \mathrm{mg} / \mathrm{dl}$, proteinuria appeared, grand mal seizures occurred and she became comatose. She was ventilated and started on daily plasma exchange (PE), which improved the level of consciousness, and the platelet count increased to $1.2 \times 10^{4} / \mu 1$ on day 11 . She was extubated in a good respiratory condition, and her proteinuria and renal function improved. However, she continued to require daily PE to maintain the platelet count.

To reduce the need for PE, she was treated with 1,000 $\mathrm{mg} /$ day of methylprednisolone as pulse therapy on days 1821 . On day 25 the platelet count improved to $6.0 \times 10^{4} / \mu 1$. PE was stopped, but two days later the platelet count had fallen to $1.3 \times 10^{4} / \mu 1$. Daily PE was resumed and administration of oral cyclosporine was started at $2.5 \mathrm{mg} / \mathrm{kg} / \mathrm{day}$. She was treated with methylprednisolone pulse therapy again on days $37-40$ because of the slow recovery of the thrombocytopenia (Fig. 1). The platelet count was around $6.0 \times 10^{4} / \mu 1$ while we 


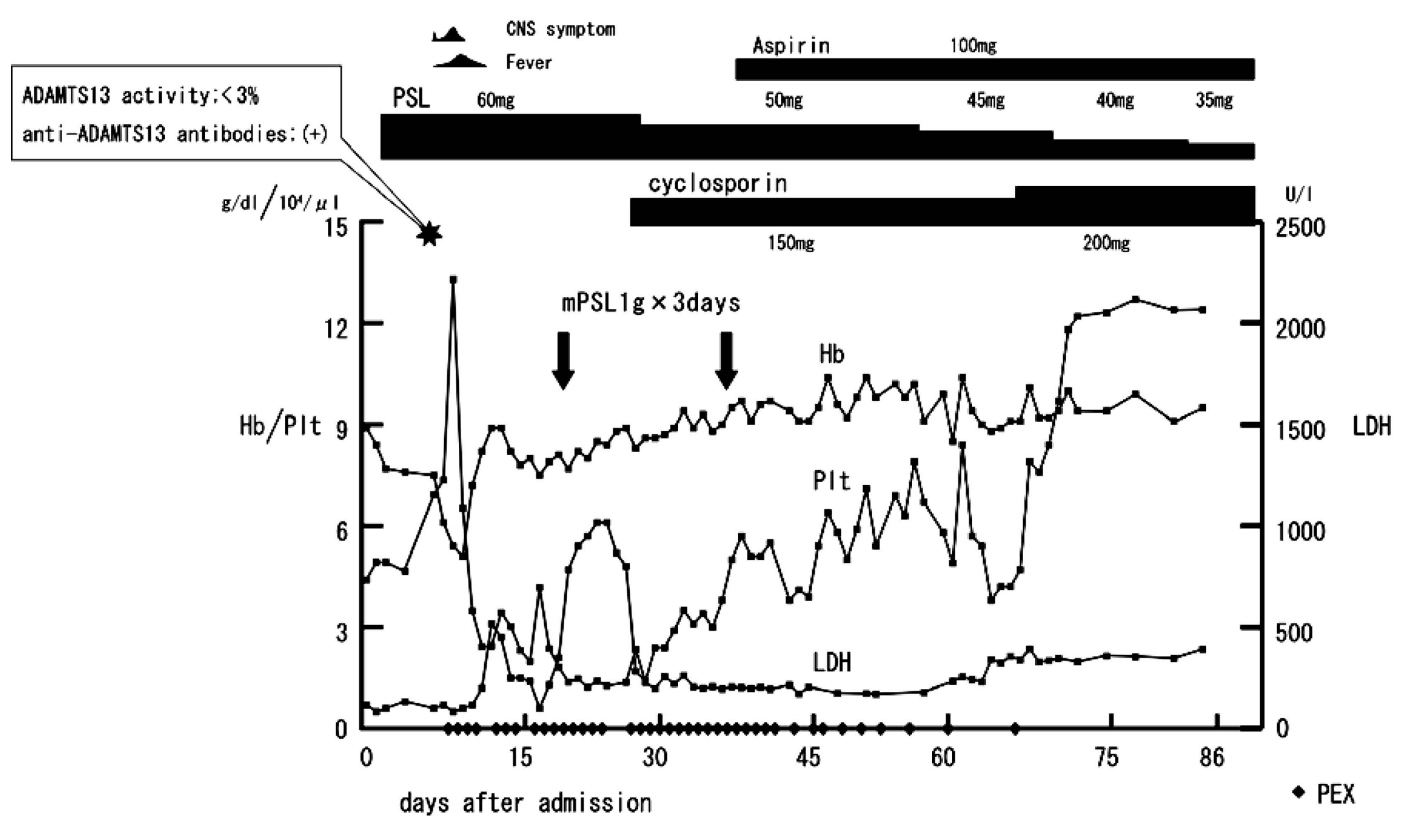

Figure 1. Clinical course after admission (laboratory data, medication, symptoms).

reduced the frequency of $\mathrm{PE}$. She was finally withdrawn from PE on day 67 after admission (total number of PE was 39). On day 68 , the dose of cyclosporine was increased to $3.3 \mathrm{mg} / \mathrm{kg} /$ day because the trough level was low $(55.8 \mathrm{ng} /$ $\mathrm{ml})$. Platelet count was more than $12.0 \times 10^{4} / \mu 1$ during tapering of oral PSL (Fig. 1).

Her proteinuria disappeared after the second series of PE and serum creatinine kinase normalized at the same time. Her titer of anti-DNA antibody (RIA) decreased to $2 \mathrm{U} / \mathrm{ml}$ on day 36 and her hematuria resolved on day 44. Her complement levels were low during hospitalization, and she had no proteinuria or hematuria. She was discharged without any clinical symptoms on the 88th day after admission. In November 2006, she is taking PSL at a dose of $12 \mathrm{mg} / \mathrm{day}$ and cyclosporine at a dose of $4.2 \mathrm{mg} / \mathrm{kg} /$ day.

\section{Discussion}

TTP was first described by Moschowitz in 1925 as a new disease characterized by the unique pathological findings of hyaline thrombi in many organs (9), and he defined the classic pentad of clinical features: thrombocytopenia, microangiopathic hemolytic anemia, neurologic symptoms and signs, renal function abnormalities and fever (10). These symptoms may, however, also be present in relapses of SLE. TTP is a rare complication of SLE, but it is important to distinguish between the two diseases because of the therapeutic implications. Detection of the fragmented peripheral RBCs helps in the early diagnosis of TTP (11). Severe ADAMTS13 deficiency and the presence of an inhibitor to ADAMTS13 may be highly specific for TTP $(12,13)$

PE was initiated for a diagnosis of TTP with thrombocytopenia, microangiopathic hemolytic anemia and neurologic symptoms. Laboratory findings showed ADAMTS13 activity of less than $3 \%$, detectable inhibitory anti-ADAMTS13 autoantibody and a normal coagulation screen. Recent reports suggest that detectable inhibitory anti-ADAMTS13 antibodies indicate a poor prognosis, a delayed response to PE, a higher plasma volume requirement to achieve complete remission, and a trend to more frequent flare-ups $(6,7)$. In addition, a high titer of anti-ADAMTS13 antibodies may be associated with a more advanced stage of the disease or refractory disease (8).

Our patient was treated with $1,000 \mathrm{mg}$ of methylprednisolone in addition to PE because of delayed platelet count recovery. Although a transient increase in the platelet count occurred after pulse methylprednisolone therapy, she continued to be dependent on PE. A number of anecdotal reports have indicated that patients with poorly responsive disease following continued PE plus glucocorticoids may benefit from the use of more intensive immunosuppressive agents, including cyclosporine $(14,15)$, cyclophosphamide (16) and rituximab (17). Among these agents, cyclophosphamide, an alkylating agent that prevents cell division by cross-linking DNA strands and decreasing DNA synthesis, induces a dose-dependent injury to the hemopoietic bone marrow (18, 19). The most common adverse effects of monoclonal antibodies, including rituximab, are myelosuppression and infusion-related and hypersensitivity reactions $(20,21)$. In contrast, cyclosporine, which lacks clinically significant myelosuppressive activity, has an immunosuppressive effect by blocking production and release of interleukin 2 and inhibiting interleukin 2-induced activation of resting $\mathrm{T}$ lymphocytes (22). Thus use of cyclosporine may represent a lower risk for patients with severe cytopenia who need immunosuppressive therapy. However, cyclosporine has not been generally used in TTP because it can itself cause TTP. Recently, anecdotal reports have indicated success following the use of cyclosporine in patients with poorly responsive disease. At relapse, reinstitution of cyclosporine treatment 
can lead to a lasting response (23-26). There are no reports of the effectiveness of cyclosporine in TTP induced by infection or the hemolytic uremic syndrome. The mechanism of action of cyclosporine in TTP is unknown, but it may be mediated through one or both of two separate pathways (27, 28 ). It may work directly as a $\mathrm{T}$ cell inactivator. $\mathrm{T}$ cell inhibition by cyclosporine might suppress anit-ADAMTS13 antibodies and improve ADAMTS13 activity. Secondly, an increase in endothelial nitric oxide activity induced by cyclosporine may inhibit platelet aggregation.

Our patient was treated with cyclosporine because she developed severe thrombocytopenia. Administration of cyclosporine and a second course of methylprednisolone pulse therapy enabled her to maintain her platelet count and to prolong the interval between PE. Her platelet counts were further increased by raising the dosage of cyclosporine to
$3.3 \mathrm{mg} / \mathrm{kg} / \mathrm{day}$, and she was able to discontinue PE. Although there are reports of TTP being associated with flareups of SLE $(29,30)$, in our case her SLE was relatively quiescent.

In summary, we present a case of refractory TTP in which remission was induced by the addition of cyclosporine to $\mathrm{PE}$ and glucocorticoid treatment. In recent studies, TTP with detectable inhibitory anti-ADAMTS13 antibodies has been linked with refractory or recurrence-prone disease. Moreover, severe ADAMTS13 deficiency coexisting with other immune-mediated diseases (in this case SLE and MG) may indicate that an autoimmune mechanism is involved in the pathogenesis. Therefore, intensive immunosuppressive therapy may be needed in addition to $\mathrm{PE}$, and it is possible that cyclosporine may be an effective treatment option in cases of TTP with ADAMTS13 inhibitors.

\section{References}

1. Fujikawa K, Suzuki H, McMullen B, Chung D. Purification of human von Willebrand factor-cleaving protease and its identification as a new member of the metalloproteinase family. Blood 98: 1662-1666, 2001.

2. Plaimauer B, Zimmermann K, Volkel D, et al. Cloning, expression, and functional characterization of the von Willebrand factorcleaving protease (ADAMTS13). Blood 100: 3626-3632, 2002.

3. Levy GG, Motto DG, Ginsburg D. ADAMTS13 turns 3. Blood 106: 11-17, 2005.

4. Uemura M, Tatsumi K, Matsumoto $M$, et al. Localization of ADAMTS13 to the stellate cells of human liver. Blood 106: 922924, 2005.

5. Chow TW, Turner NA, Chintagumpala M, et al. Increased von Willebrand factor binding to platelets in single episode and recurrent types of thrombotic thrombocytopenic purpura. Am J Hematol 57: 293-302, 1998.

6. Coppo P, Wolf M, Veyradier A, et al. Prognostic value of inhibitory anti-ADAMTS13 antibodies in adult-acquired thrombotic thrombocytopenic purpura. Br J Haematol 132: 66-74, 2006.

7. Zheng XL, Kaufman RM, Goodnough LT, Sadler JE. Effect of plasma exchange on plasma ADAMTS13 metalloprotease activity, inhibitor level, and clinical outcome in patients with idiopathic and nonidiopathic thrombotic thrombocytopenic purpura. Blood 103: 4043-4049, 2004.

8. Tsai HM, Li A, Rock G. Inhibitors of von Willebrand factorcleaving protease in thrombotic thrombocytopenic purpura. Clin Lab 47: 387-392, 2001.

9. Moschowitz E. An acute febrile pleiochromic anemia with hyaline thrombosis of the terminal arterioles and capillaries. Arch Intern Med 36: 89-93, 1925.

10. Amorosi E, Ultmann J. Thrombotic thrombocytopenic purpura: Report of 16 cases and review of the literature. Medicine 45: 139$159,1966$.

11. Hamasaki K, Mimura T, Kanda H, et al. Systemic lupus erythematosus and thrombotic thrombocytopenic purpura: a case report and literature review. Clin Rheumatol 22: 355-358, 2003.

12. Tsai HM. Advances in the pathogenesis, diagnosis, and treatment of thrombotic thrombocytopenic purpura. J Am Soc Nephrol 14: 1072-1081, 2003.

13. Vesely SK, George JN, Lammle B, et al. ADAMTS13 activity in thrombotic thrombocytopenic purpura-hemolytic uremic syndrome: relation to presenting features and clinical outcomes in a prospective cohort of 142 patients. Blood 102: 60-68, 2003.

14. Kierdorf H, Maurin N, Heintz B. Cyclosporine for thrombotic thrombocytopenic purpura. Ann Intern Med 118: 987-988, 1993.

15. Pasquale D, Vidhya R, DaSilva K, et al. Chronic relapsing thrombotic thrombocytopenic purpura: role of therapy with cyclosporine. Am J Hematol 57: 57-61, 1998.

16. Allan DS, Kovacs MJ, Clark WF. Frequently relapsing thrombotic thrombocytopenic purpura treated with cytotoxic immunosuppressive therapy. Haematologica 86: 844-850, 2001.

17. George JN. Controlling chronic TTP. Blood 106: 1896, 2005.

18. Berchtold P, Seitz M. Immunosuppression-a tightrope walk between iatrogenic harm and therapy. Schweiz Med Wochenschr 126: 1603-1609, 1996 (in German, Abstract in English).

19. Lohrmann HP. The problem of permanent bone marrow damage after cytotoxic drug treatment. Oncology 41: 180-184, 1984.

20. Cersosimo RJ. Monoclonal antibodies in the treatment of cancer, Part 1. Am J Health Syst Pharm 60: 1531-1548, 2003.

21. Leone G, Sica S, Voso MT, Rutella S, Pagano L. Treatment of acute leukaemias with monoclonal antibodies: current status and future prospects. Cardiovasc Hematol Agents Med Chem 4: 33-52, 2006.

22. Ishida Y, Matsuda H, Kida K. Effect of cyclosporin A on human bone marrow granulocyte-macrophage progenitors with anti-cancer agents. Acta Paediatr Jpn 37: 610-613, 1995.

23. Nosari A, Bernuzzi P, Corneo R. Late response to cyclosporine in refractory thrombotic thrombocytopenic purpura. Int $\mathrm{J}$ Hematol 76: 284-286, 2002.

24. Cataland SR, Wu HM. Immunotherapy for thrombotic thrombocytopenic purpura. Curr Opin Hematol 12: 359-363, 2005.

25. Itala M, Remes K. Excellent response of refractory life-threatening thrombotic thrombocytopenic purpura to cyclosporine treatment. Clin Lab Haematol 26: 65-67, 2004.

26. Jayabose S, Levendoglu-Tugal O, Ozkayanak MF, Chao CP, Cuccovia B, Sandoval C. Use of vincristine and cyclosporine in childhood thrombotic thrombocytopenic purpura. J Pediatr Hematol Oncol 25: 421-425, 2003.

27. Hand JP, Lawlor ER, Yong CKK, Davis JH. Successful use of cyclosporine $\mathrm{A}$ in the treatment of refractory thrombotic thrombocytopenic purpura. Br J Haematol 100: 597-599, 1998.

28. Tak-Tai YUE, Samuel Ka-Shun FUNG, Wai-Kay TSANGl, et al. Refractory thrombotic thrombocytopenic purpura in a lupus nephritis patient. Hong Kong Journal of Nephrology 4: 51-53, 2002.

29. Kapoulas S, Liakos S, Karkavelas G, et al. Thrombotic thrombocytopenic purpura associated with rapidly progressive lupus nephritis: report of two cases. Clin Nephrol 63: 297-301, 2005.

30. Starck M, Abedinpour F, Dendorfer U, et al. Acquired thrombotic 
DOI: 10.2169/internalmedicine.46.6192

thrombocytopenic purpura as the presenting symptom of systemic lupus erythematosus. Successful treatment with plasma exchange and immunosuppression-report of two cases. Eur J Haematol 75: 436-440, 2005.

(C) 2007 The Japanese Society of Internal Medicine http://www.naika.or.jp/imindex.html 